\title{
Using Lightweight Materials to Enhance Thermal Resistance of Asphalt Mixture for Cooling Asphalt Pavement
}

\author{
Haibin Deng, ${ }^{1}$ Deyi Deng, ${ }^{1}$ Yinfei Du $\mathbb{D}^{2},{ }^{2}$ and Xinmin Lu ${ }^{1}$ \\ ${ }^{1}$ Highway Administration Bureau of Huzhou, Zhejiang 313000, China \\ ${ }^{2}$ School of Civil Engineering, Central South University, Changsha, Hunan 410075, China \\ Correspondence should be addressed to Yinfei Du; yfdu_csu@csu.edu.cn
}

Received 17 June 2019; Revised 31 July 2019; Accepted 7 August 2019; Published 4 September 2019

Academic Editor: Libo Yan

Copyright (c) 2019 Haibin Deng et al. This is an open access article distributed under the Creative Commons Attribution License, which permits unrestricted use, distribution, and reproduction in any medium, provided the original work is properly cited.

This study aims to enhance the thermal resistance of asphalt mixture to cool asphalt pavement. Four kinds of asphalt mixtures were prepared by replacing basalt aggregate and limestone mineral powder with shale ceramsite (SC) and fly ash cenosphere (FAC), respectively. A series of experiments, including environment scanning electron microscope test, thermophysical parameter test, indoor irradiation test, shear strength test, and rutting test, were performed to verify the purpose of this study. The results show that using low-density SC and FAC could produce lightweight asphalt mixtures, which had lower thermal conductivity than control asphalt mixture. The indoor irradiation test shows that the resultant asphalt mixtures had lower temperatures at the depth of lower than $4 \mathrm{~cm}$. The addition of SC had a negative effect on the shear strength and dynamic stability of asphalt mixture. However, the two indicators increased due to the addition of FAC. The results presented in this study indicate that it is feasible to use lightweight aggregate to prepare low-thermal-conductivity asphalt mixture and use this kind of asphalt mixture to cool asphalt pavement.

\section{Introduction}

Asphalt pavement has a low solar albedo of less than 0.1 $[1,2]$, which is responsible for its high heat absorbing capacity and pavement temperature. For example, it was reported that the maximum temperature of asphalt pavement in summer could reach up to more than $65^{\circ} \mathrm{C}$ [3-5]. Hightemperature rutting is very easy to occur when the pavement is subjected to heavy vehicle loads [6,7]. The existing solutions for rutting focus on improving the high-temperature performances of the asphalt binder and mixture, such as rubber asphalt [8], high modulus asphalt [9], semiflexible asphalt mixture [10], etc. However, the commonly used materials generally do not consider the significant influence of pavement temperature on the rutting development. Because asphalt mixture is featured of temperature sensitivity, cool asphalt pavement should be applied to counter the rutting distress.

There are many technologies for cooling asphalt pavement, such as solar reflective coating [11], phase change material [12], water retentive pavement [13], and solar energy collector [14], etc. Besides, thermally modified asphalt mixture has become a popular topic in an attempt to cool asphalt pavement, because the heat conduction process in asphalt pavement can be regulated by changing the thermal parameters of different asphalt layers [15]. It was found that to decrease the heat absorption of asphalt pavement, which was achieved by enhancing the thermal resistance of asphalt mixture, was expected to mitigate the above problem $[16,17]$.

There are many ways to enhance the thermal resistance of asphalt mixture, which was always realized by increasing the air void content in asphalt mixture $[18,19]$. The most used low-thermal-conductivity asphalt mixture is porous asphalt mixture that was used in permeable pavement $[20,21]$. However, it was found that the coarse surface always resulted in a low solar reflectance [22], raising pavement temperature in sunny days [23]. Thus, adding lightweight aggregate or filler in asphalt mixture became a potential way for preparing high-thermal-resisting asphalt mixture. 
To our knowledge, some fillers, such as recycled tyre rubber [24], diatomite [25], waste ceramic aggregate [26], glass cenosphere [27], and encapsulated cigarette butt [28], have been incorporated to reduce the thermal conductivity of asphalt mixture. Besides the above lightweight materials, both shale ceramsite (SC) and fly ash cenosphere (FAC) also have large air void contents. However, very limited studies have been reported to use SC and FAC to prepare asphalt mixture and evaluate the thermal and rutting performances of this kind of asphalt mixture.

\section{Objective}

This work aims at preparing a low-thermal-conductivity asphalt mixture and evaluating its thermal and rutting performances to facilitate its application in fighting rutting distress. A kind of lightweight aggregate of SC was used to replace basalt aggregate based on an equivalent volume concept. In the same way, FAC with particle diameter smaller than $0.075 \mathrm{~mm}$ was also used to replace limestone mineral powder. Thermal performances, including thermophysical parameters and cooling effect, were evaluated by performing thermal conductivity and indoor irradiation tests. Shear strength was measured, because rutting distress is highly related to the shear performance of asphalt mixture [6]. The dynamic stability was also measured to directly present the rutting resistance of the designed asphalt mixture.

The process of mixture design and performance evaluation is shown in Figure 1.

\section{Materials and Methods}

3.1. Materials. An AC-13 asphalt mixture, which was comprised of basalt aggregate, limestone mineral powder, and base asphalt, was used as control asphalt mixture. SC was used as lightweight aggregate, and FAC was used as lightweight mineral filler. The representative morphology images of FAC and SC are shown in Figure 2.

In total, four different asphalt mixtures with very similar aggregate gradations were designed. Their aggregate and filler compositions are presented in Table 1. And the aggregate gradation of control asphalt mixture is shown in Table 2. The asphalt content of control asphalt mixture was $4.8 \%$. Because of the higher moisture absorption ratio of SC, the mixtures containing SC were repeatedly designed to determine their specific asphalt contents. According to the results, the asphalt contents of Mixture \#1, Mixture \#2, and Mixture \#3 were 5.2\%, 5.3\%, and $5.2 \%$, respectively.

\subsection{Test Methods}

3.2.1. Environment Scanning Electron Microscope (ESEM) Test. A Quanta 200 environment scanning electron microscope (ESEM) (FEI Co. Ltd., USA) was used to characterize the internal microscope images of SC and FAC. SC was broken off to obtain clean and smooth sections as far as possible. TThe resultant particles were first dried for over 2 hours and then coated with gold. In order to obtain clear SEM images, the voltage for SC was $20.00 \mathrm{kV}$, and the voltage for FAC was $2.00 \mathrm{kV}$. All the images were magnified by 200 times.

3.2.2. Thermal Conductivity Test. Each Marshall specimen was cut into several slices with smooth surfaces. A DRE-2C thermal conductivity meter (Xiangtan Instruments and Meters, Hu'nan Province, China), which was based on the transient plane heat source method, was used to measure the thermal conductivity and thermal diffusivity (Figure 3). In the test process, a test probe was placed between two mixture slices and the two slices were closely contacted with each other. The specific heat capacity was computed using the values of bulk density, thermal conductivity, and thermal diffusivity.

3.2.3. Indoor Irradiation Test. Each Marshall asphalt mixture specimen was thermally insulated by spraying foam around it. Several incandescent lamps with electric power of $275 \mathrm{~W}$, which were placed over asphalt mixture specimens with a height of $90 \mathrm{~cm}$, were used to simulate solar radiation (Figure 4). The irradiation lasted for 200 minutes. The coarse upper surface always led to nonuniform temperature distribution, which made it difficult to accurately measure the actual surface temperature using a portable infrared thermometer. So, the upper surface temperature profile was recorded by an E6 infrared imaging instrument (FLIR Co. Ltd., USA). The temperature profiles at the depths of $2 \mathrm{~cm}$ and $4 \mathrm{~cm}$ and at the bottom surface were recorded by a 16channel temperature logger (TP700-16, Shenzhen Toprie Electronics Co. Ltd., China).

3.2.4. Shear Strength. An automatic strength tester was used to perform the uniaxial compression test and the splitting tensile test, which used the standard Marshall specimen. The detailed loading rates were $2 \mathrm{~mm} / \mathrm{min}$ and $50 \mathrm{~mm} / \mathrm{min}$, respectively, according to the Chinese specification JTG E202011 [29]. The shear strength was computed according to equations (1)-(4) based on the Mohr-Coulomb failure theory [30]:

$$
\begin{aligned}
\tan \alpha & =\frac{\left|\sigma_{\mathrm{UCT}}\right|-4\left|\sigma_{\mathrm{ST}}\right|}{\left|\sigma_{\mathrm{UCT}}\right|-2\left|\sigma_{\mathrm{ST}}\right|}, \\
\varphi & =\sin ^{-1}(\tan \alpha), \\
C & =\left(\frac{2-\tan \alpha}{\cos \varphi}\right) \sigma_{\mathrm{ST}}, \\
\tau & =C+\sigma_{\mathrm{UCT}} \tan \varphi,
\end{aligned}
$$

where $\sigma_{\mathrm{UCT}}=$ uniaxial compressive strength, $\mathrm{MPa} ; \sigma_{\mathrm{ST}}=$ splitting tensile strength, $\mathrm{MPa} ; C=$ cohesion, $\mathrm{MPa}$; and $\varphi=$ angle of internal friction. 


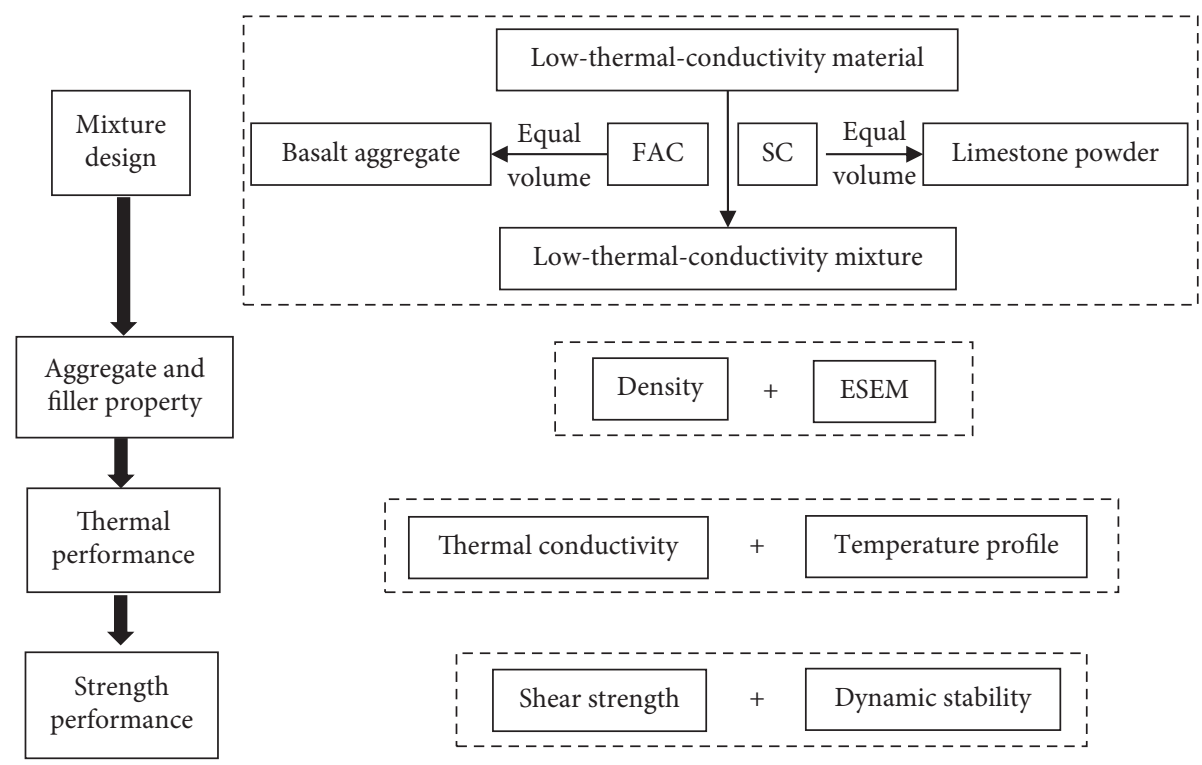

FIgURE 1: Flow chart of the process of mixture design and performance evaluation.

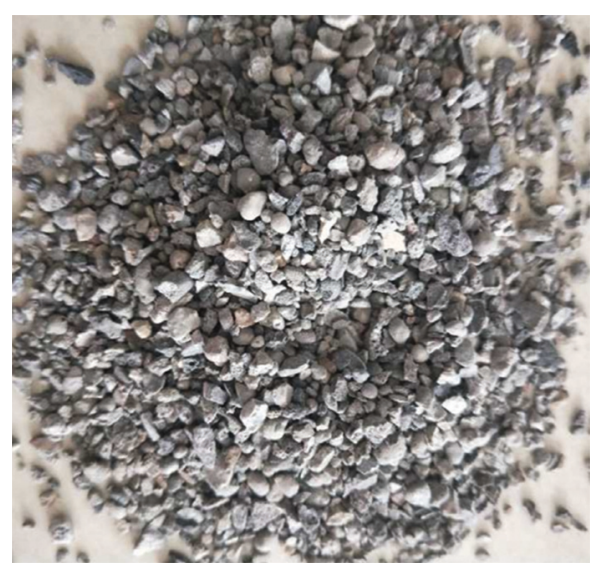

(a)

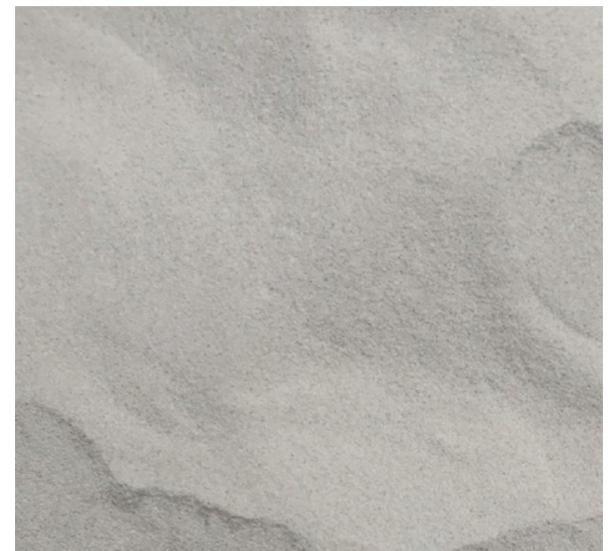

(b)

FIGURE 2: Representative morphology images of lightweight aggregate: (a) SC with particle size of 3-5 mm; (b) FAC.

TABLE 1: Mass ratios of the aggregate and filler in AC-13 asphalt mixture (wt.\%).

\begin{tabular}{|c|c|c|c|c|c|c|c|}
\hline \multirow{2}{*}{ Mixture type } & \multicolumn{3}{|c|}{ Basalt aggregate } & \multicolumn{2}{|c|}{ SC } & \multirow{2}{*}{ Limestone powder } & \multirow{2}{*}{ FAC } \\
\hline & $5-15 \mathrm{~mm}$ & $3-5 \mathrm{~mm}$ & $0-3 \mathrm{~mm}$ & $3-5 \mathrm{~mm}$ & $0-3 \mathrm{~mm}$ & & \\
\hline Control mixture & 25 & 30 & 43 & NA & NA & 2 & NA \\
\hline Mixture \#1 & 27 & 37 & NA & $\mathrm{NA}$ & 29 & 7 & $\mathrm{NA}$ \\
\hline Mixture \#2 & 29 & 25 & NA & 11 & 28 & 7 & NA \\
\hline Mixture \#3 & 27 & 35 & NA & $\mathrm{NA}$ & 33 & NA & 5 \\
\hline
\end{tabular}

TABLE 2: Aggregate gradation of control asphalt mixture.

\begin{tabular}{|c|c|c|c|c|c|c|c|c|c|c|}
\hline Sieve size $(\mathrm{mm})$ & 16.0 & 13.2 & 9.5 & 4.75 & 2.36 & 1.18 & 0.6 & 0.3 & 0.15 & 0.075 \\
\hline Passing ratio (wt.\%) & 100 & 96.0 & 82.0 & 48.8 & 27.8 & 20.6 & 15.1 & 9.9 & 7.6 & 6.1 \\
\hline
\end{tabular}




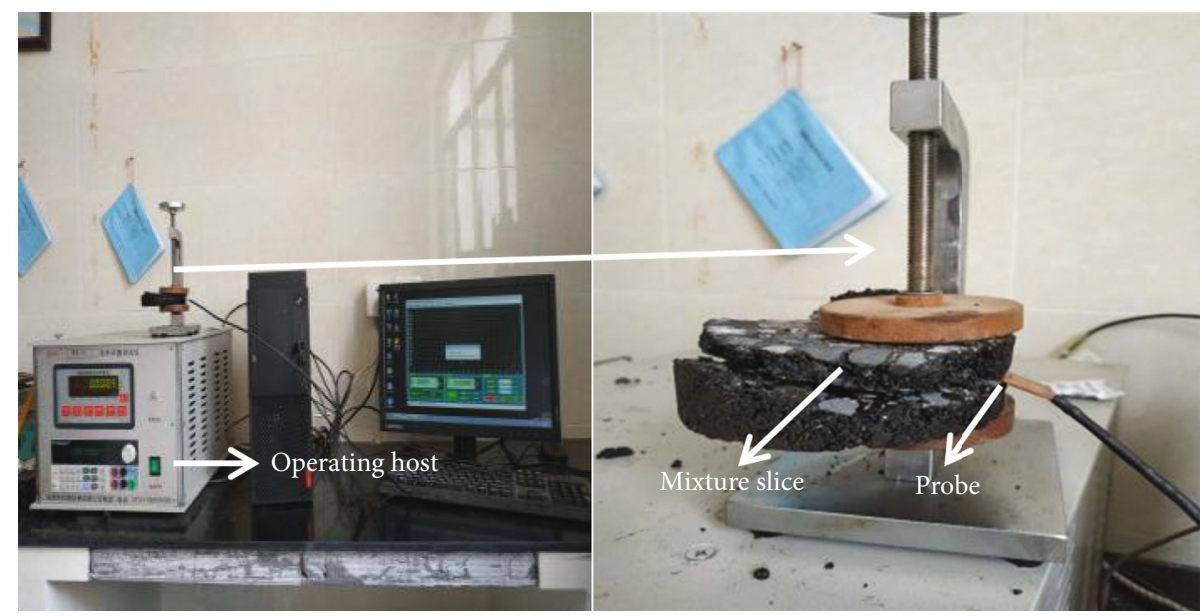

Figure 3: Testing instrument of thermal conductivity.

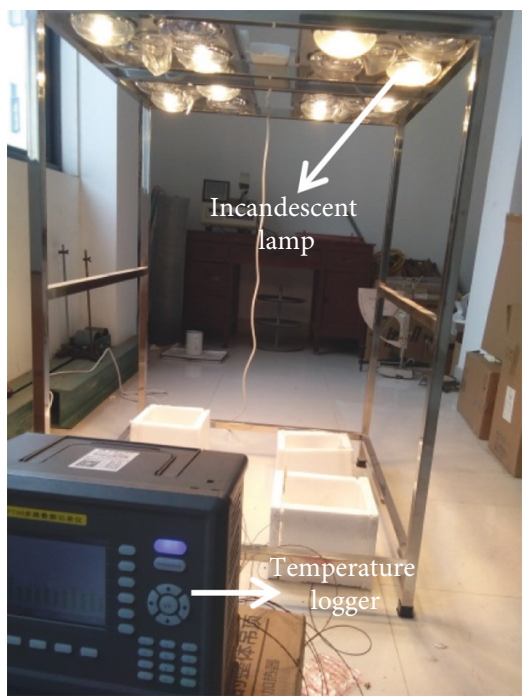

(a)

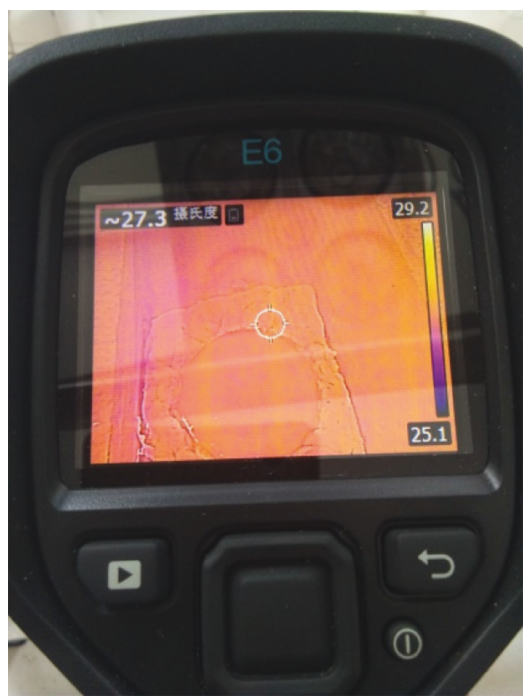

(b)

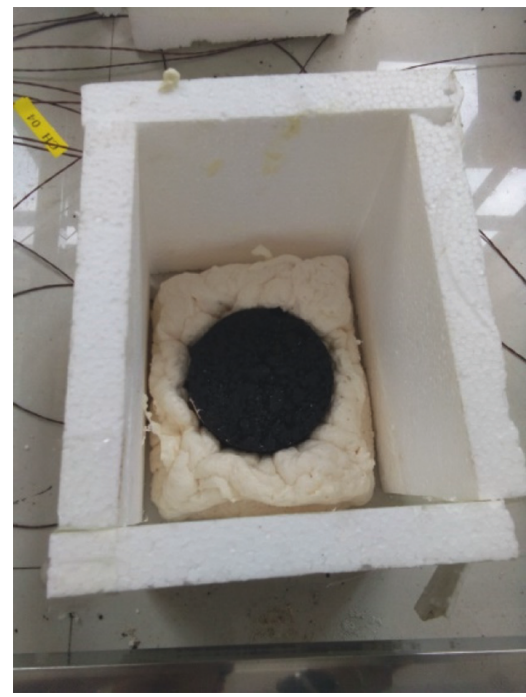

(c)

FIGURE 4: Schematic diagrams of indoor irradiation test: (a) irradiation instrument; (b) infrared imaging instrument; (c) thermally insulated specimen.

3.2.5. Rutting Test. According to the mix proportions of the designed asphalt mixtures, rutting plates $(300 \mathrm{~mm} \times 300 \mathrm{~mm} \times 50 \mathrm{~mm})$ were prepared. And then, the specimens were heated in a temperature box with a constant temperature of $60^{\circ} \mathrm{C}$ for at least five hours. Finally, the specimens were tested by a flat rubber wheel tracking tester according to the Chinese specification JTG E20-2011 [29]. An indicator of dynamic stability, which was computed using equation (5), was used to evaluate the rutting performance of asphalt mixture:

$$
\mathrm{DS}=\frac{\left(t_{2}-t_{1}\right)}{d_{2}-d_{1}} \times N,
$$

where $\mathrm{DS}=$ dynamic stability, times $/ \mathrm{min} ; t_{1}=45 \mathrm{~min}$; $t_{2}=60 \mathrm{~min} ; d_{1}=$ specimen deformation at the time of $t_{1}, \mathrm{~mm}$; $d_{2}=$ specimen deformation at the time of $t_{2}, \mathrm{~mm}$; and $N=42$ times/min.

\section{Results and Discussion}

\subsection{Aggregate and Filler Properties}

4.1.1. Density Properties of Aggregates and Fillers. The physical properties, including apparent specific density, bulk specific density, and moisture absorption ratio, of SC were measured using the same methods for aggregate [31]. In fact, the tested moisture absorption ratio might be largely lower than the actual one. On the one hand, the large air void had a low surface tension force, and the absorbed moisture might leak from the pores. On the other hand, the lightweight aggregate might not be able to sufficiently absorb water only by physical absorption under ambient atmosphere pressure [32]. The physical properties of the above materials are shown in Table 3 . The results show that the moisture absorption ratio of SC was over ten times higher than that of 
TABLe 3: Physical properties of aggregates and fillers.

\begin{tabular}{|c|c|c|c|c|c|c|c|}
\hline \multirow{2}{*}{ Mixture type } & \multicolumn{3}{|c|}{ Basalt aggregate } & \multicolumn{2}{|c|}{ SC } & \multirow{2}{*}{ Limestone powder } & \multirow{2}{*}{ FAC } \\
\hline & $5-15 \mathrm{~mm}$ & $3-5 \mathrm{~mm}$ & $0-3 \mathrm{~mm}$ & $3-5 \mathrm{~mm}$ & $0-3 \mathrm{~mm}$ & & \\
\hline Apparent specific density & 2.633 & 2.641 & 2.543 & 1.378 & 1.385 & 2.788 & 0.413 \\
\hline Bulk specific density & 2.599 & 2.586 & 2.586 & 1.267 & 1.251 & NA & NA \\
\hline Moisture absorption ratio (\%) & 0.49 & 0.81 & 3.33 & 6.42 & 8.61 & NA & NA \\
\hline
\end{tabular}

basalt aggregate with the same aggregate size range. The higher moisture absorption ratio or higher air void content of SC provided this material with a lower density and lower thermal conductivity. In addition, we can find that the apparent density of FAC was much lower than that of limestone powder, which could ensure the low thermal conductivity of FAC than limestone powder.

4.1.2. ESEM Images of Aggregates and Fillers. In order to reveal the internal pore characteristic of SC and provide an evidence for the measured data in Table 3, the ESEM image of the broken section of SC was taken, shown in Figure 5(a). Also, the morphology of FAC was studied.

It was very evident that there were many large pores in SC. These pores resulted in low density and high moisture absorption ratio of SC, shown in Table 3. Figure 5(b) shows that most of FAC looked like spherical particles, together with some broken pieces.

4.2. Density Property of Asphalt Mixture. The bulk specific densities of these asphalt mixtures are shown in Table 4. Because of the addition of porous aggregate, the bulk specific density of the designed mixture was reduced by over $19 \%$. On the one hand, the lower density allowed this kind of mixture to be able to be used in bridge pavement construction. On the other hand, the lower bulk density of the designed mixture would reduce its thermal conduction performance, which would facilitate its application in cooling pavement.

4.3. Thermophysical Parameter. The measured thermal conductivity and computed specific heat capacity are shown in Table 5.

Table 5 shows that the additions of SC and FAC both reduced the thermal conductivity and increased the specific heat capacity. Specifically, the thermal conductivities of Mixture \#2 and \#3 reduced by $28.6 \%$ and $35.3 \%$, respectively, compared to that of control mixture. Meanwhile, the specific heat capacities of the above two mixtures increased by $25.7 \%$ and $39.0 \%$, respectively. From Table 1, it can be found that the mass content of SC in Mixture \#2 was higher than the total mass content of SC and FAC in Mixture \#3. Nevertheless, the thermal performances of Mixture \#3 were improved by more extent than those of Mixture \#2. The result was caused by the lower density of FAC compared with that of SC. According to the results reported in Refs. [16, 17], applying low-thermal-conductivity asphalt mixture in the top layer would prevent solar heat to be absorbed by asphalt mixture, thereby resulting in higher surface temperature.
Transferring of less heat into asphalt pavement resulted in reduced temperature in the middle and bottom layers.

4.4. Temperature Distribution. The infrared images of the upper surface were captured every five minutes. The infrared images at two different moments are shown in Figures 6(a) and 6(b), respectively. It can be found that the temperature distributed unevenly, which indicates that it was impossible to represent the surface temperature using a single temperature. In order to accurately present the surface temperature evolution, all the infrared images were processed by FLIR Tools software to get their average temperatures, and then these average temperatures were referred to be the surface temperatures (Figure 6(c)). In addition, the temperatures recorded by temperature probes were used to represent the inner temperatures of mixture specimens. The detailed temperature profiles at four different depth locations are shown in Figure 7.

Figure 7 shows that the four types of asphalt mixture presented different temperature distributions at any locations. Specifically, the upper surface temperature and the temperature at the depth of $2 \mathrm{~cm}$ increased with the increasing thermal resistance of asphalt mixture. Instead, the temperature at the depth of $4 \mathrm{~cm}$ and the bottom surface temperature reduced with the increasing thermal resistance of asphalt mixture. For example, the surface temperatures of Mixture \#1, Mixture \#2, and Mixture \#3 were $1.7^{\circ} \mathrm{C}, 2.1^{\circ} \mathrm{C}$, and $3.1^{\circ} \mathrm{C}$ higher than that of control mixture, respectively. And the temperatures of Mixture \#1, Mixture \#2, and Mixture \#3 at the depth of $4 \mathrm{~cm}$ were $1.62^{\circ} \mathrm{C}, 3.13^{\circ} \mathrm{C}$, and $4.39^{\circ} \mathrm{C}$ lower than that of control mixture, respectively.

From the above results, it can be concluded that using low-thermal-conductivity asphalt mixture in the top asphalt layer is adverse to mitigating the urban heat island effect, but beneficial for reducing high-temperature rutting distress, because the urban heat island effect is directly related to upper surface temperature $[33,34]$ while rutting distress is very easy to occur in the middle asphalt layer $[35,36]$.

4.5. Shear Strength. The results of uniaxial compressive strength and splitting tensile strength are shown in Figure 8. The results of shear strength, which are shown in Figure 9, were computed using the results shown in Figure 8.

The uniaxial compressive strength and splitting tensile strength presented similar varying trends for different asphalt mixtures. In particular, Mixture \#3 had a higher uniaxial compressive strength and splitting tensile strength than the other mixtures, which was largely attributed to the improved performance of asphalt matrix resulted from the addition of FAC. The comparison between Figures 8 and 9 


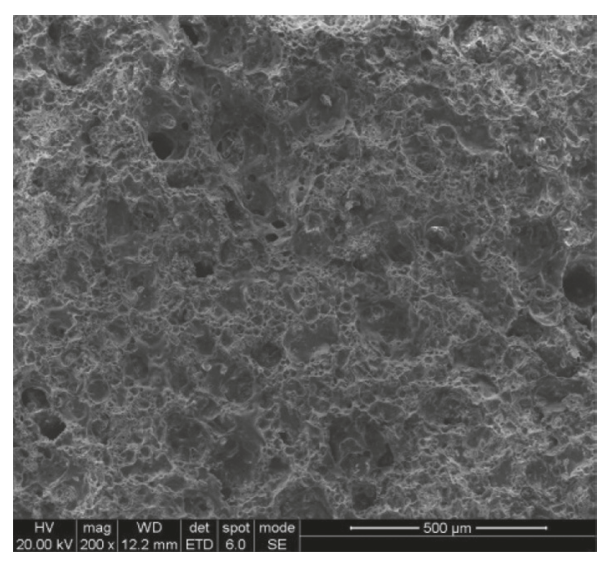

(a)

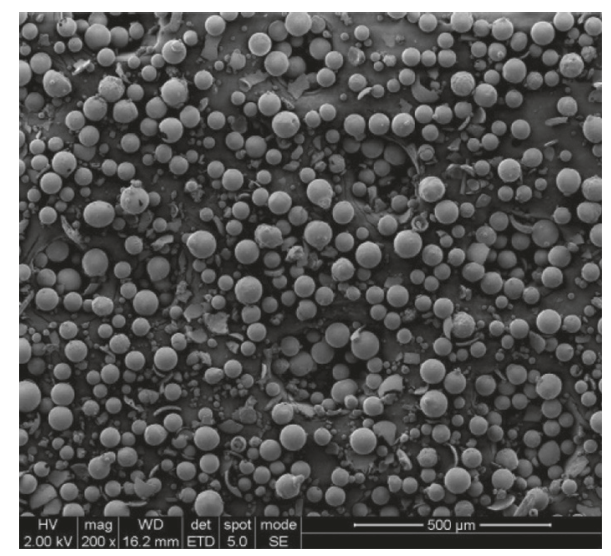

(b)

Figure 5: ESEM images of (a) SC and (b) FAC.

TABLE 4: Bulk specific densities of different asphalt mixtures.

\begin{tabular}{lcccc}
\hline Mixture type & Control mixture & Mixture \#1 & Mixture \#2 & Mixture \#3 \\
\hline Bulk specific density & 2.332 & 1.884 & 1.827 & 1.794 \\
\hline
\end{tabular}

TABLE 5: Results of thermophysical parameters.

\begin{tabular}{|c|c|c|c|c|}
\hline Thermal parameter & Control mixture & Mixture \#1 & Mixture \#2 & Mixture \#3 \\
\hline Thermal conductivity $(\mathrm{W} /(\mathrm{m} \cdot \mathrm{K}))$ & 1.2918 & 1.0449 & 0.9226 & 0.8356 \\
\hline Specific heat capacity $(\mathrm{W} /(\mathrm{kg} \cdot \mathrm{K}))$ & 717.73 & 1039.19 & 1119.2 & 1237.12 \\
\hline
\end{tabular}

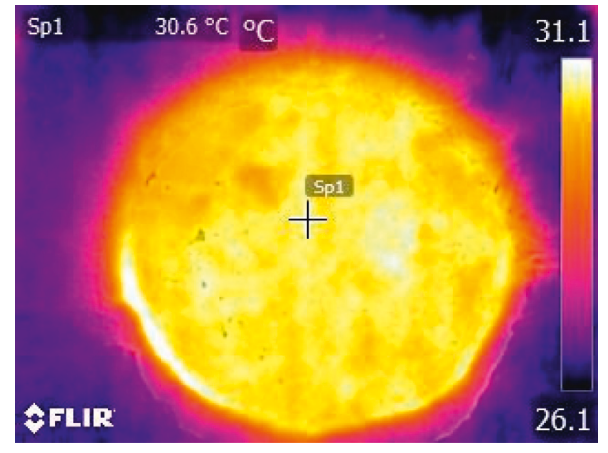

(a)

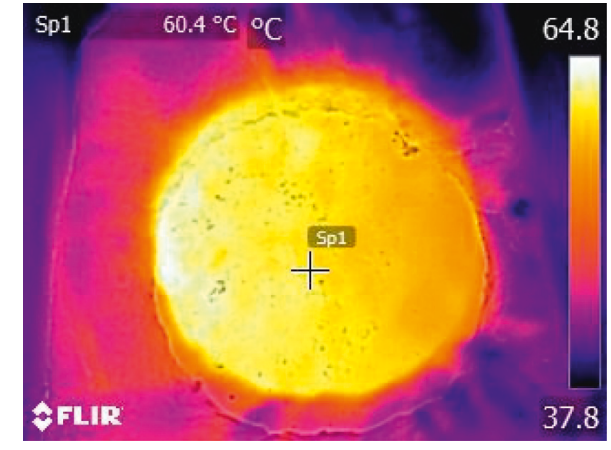

(b)

FIgURE 6: Continued. 


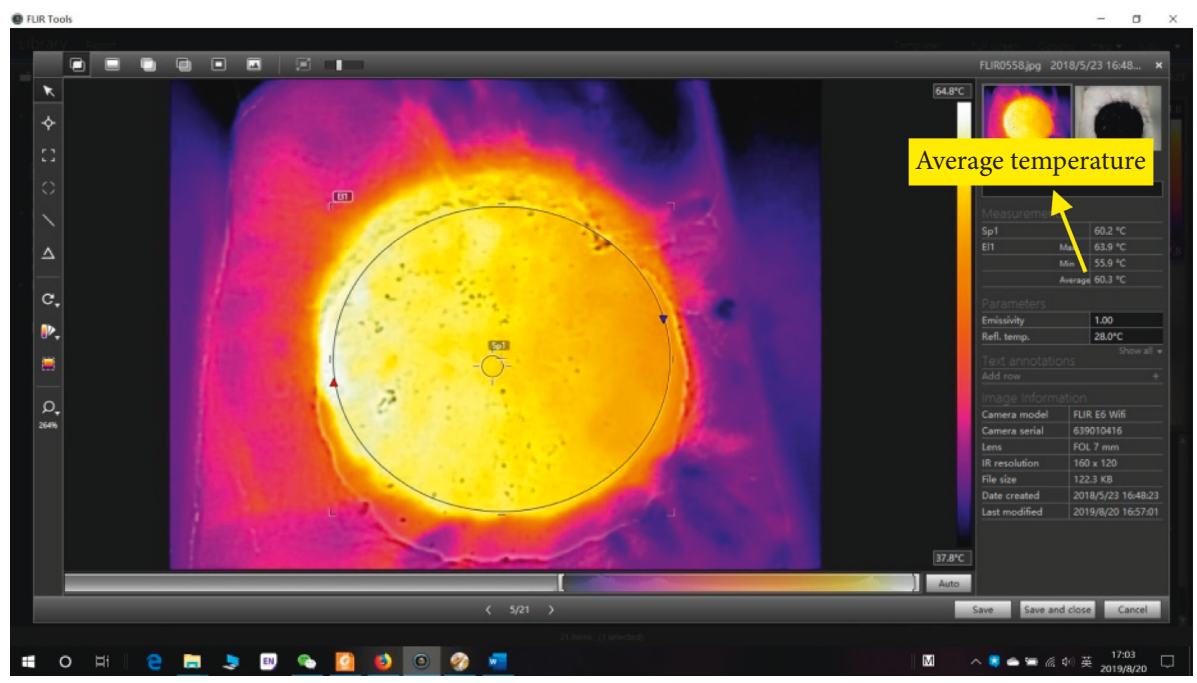

(c)

FIGURE 6: Infrared images of the control mixture specimen: (a) at the beginning of irradiation; (b) at the end of irradiation; (c) the processing interface of the recorded temperature data.

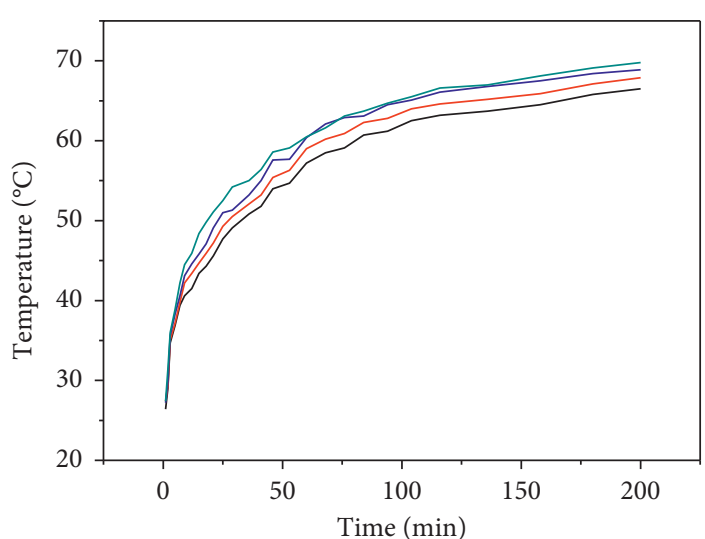

$\begin{array}{ll}\text { Control mixture } & - \text { Mixture \#2 } \\ \text { Mixture \#1 } & \text { Mixture \#3 }\end{array}$

(a)

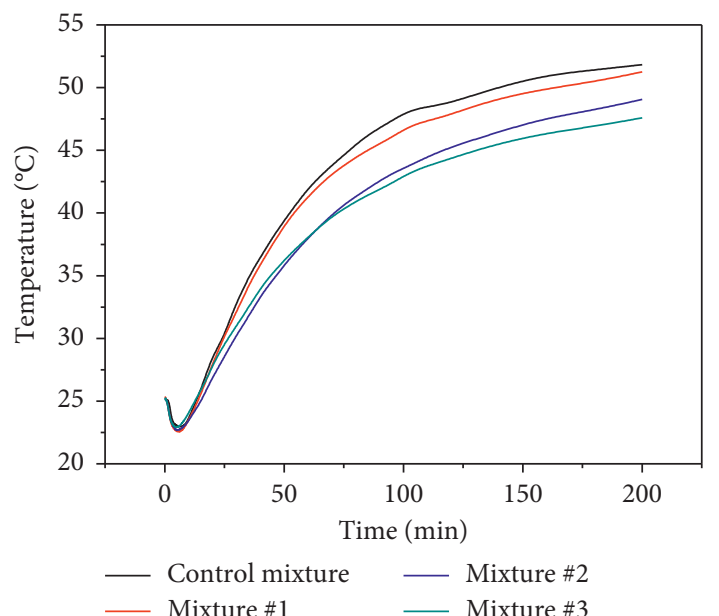

(c)

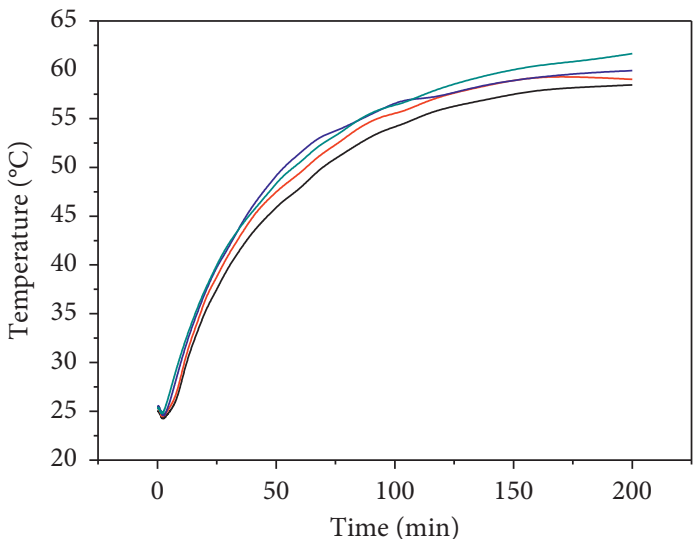

- Control mixture - Mixture \#2

— Mixture \#3

(b)

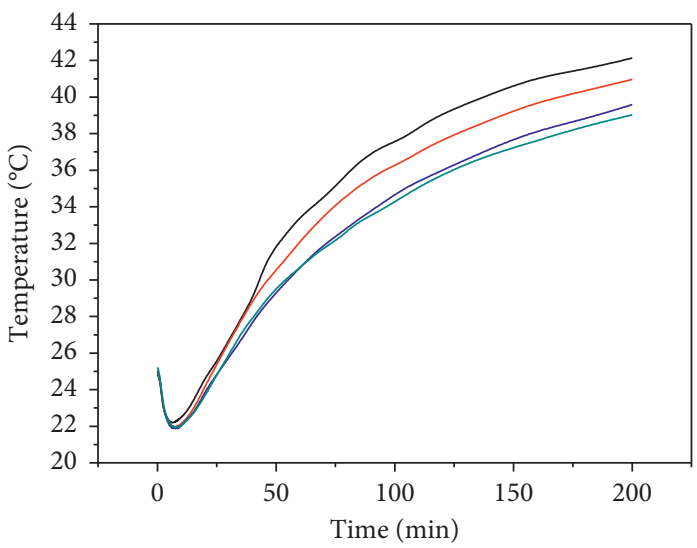

$\begin{array}{ll}\text { Control mixture } & \text { Mixture \#2 } \\ \text { Mixture \#1 } & \text { Mixture \#3 }\end{array}$

(d)

Figure 7: Temperature profiles: (a) upper surface; (b) at the depth of $2 \mathrm{~cm}$; (c) at the depth of $4 \mathrm{~cm}$; (d) bottom surface. 


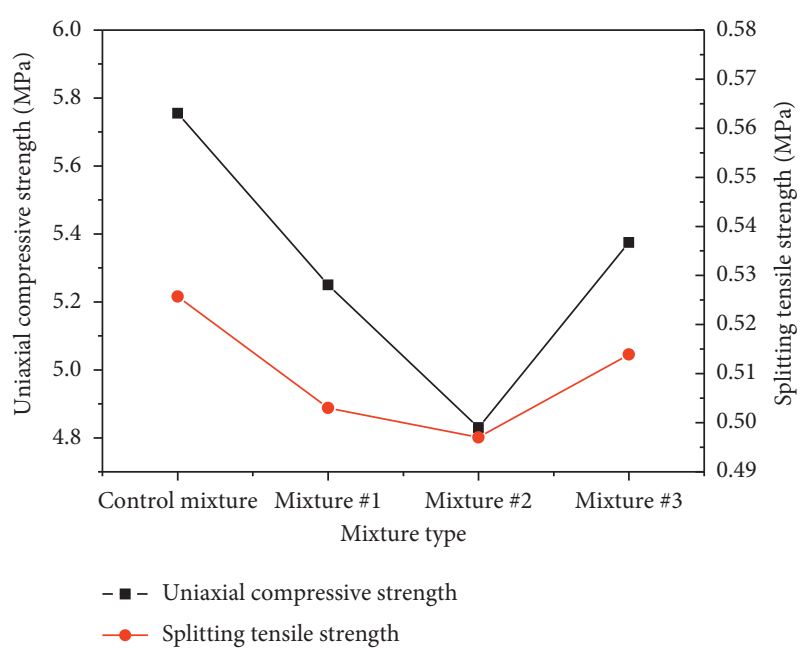

FIGURE 8: Results of uniaxial compression strength and splitting tensile strength.

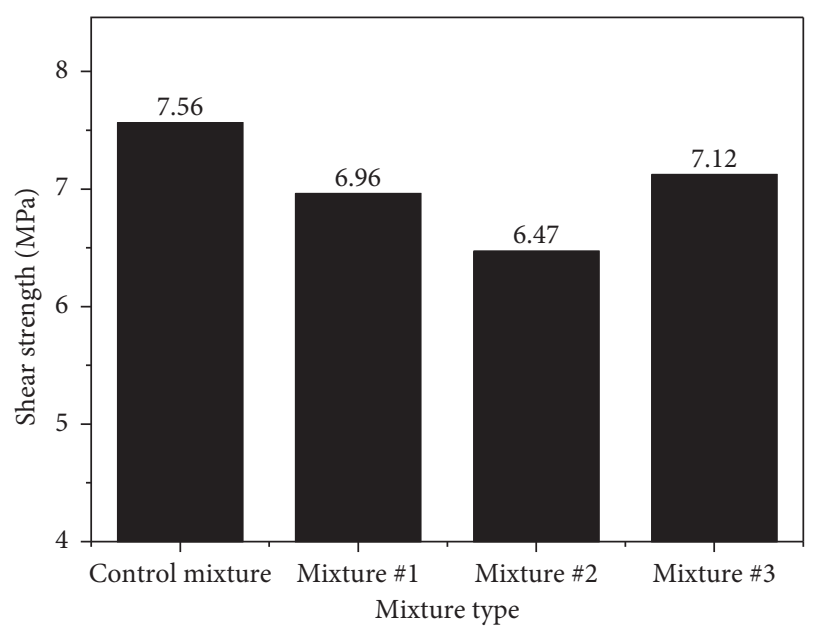

FIGURE 9: Results of computed shear strength.

indicates that the three strength indicators had the same varying trends. The shear strengths of Mixture \#1 and Mixture \#2 reduced by $7.9 \%$ and $14.4 \%$, respectively. In contrast, the shear strength of Mixture \#3 was slightly higher than Mixture \#1, which was attributed to the addition of FAC that might increase its adhesive strength with asphalt binder $[37,38]$. Although the addition of lightweight aggregate could increase the thermal resistance of asphalt mixture, the low-thermal-conductivity asphalt mixture showed lower strength compared to control asphalt mixture. It is suggested to add some reinforcing agents (e.g., fibers) in future studies to prepare low-thermal-conductivity asphalt mixture with high strength.

4.6. Dynamic Stability. According to the mixture proportion shown in Table 1, rutting specimens with size of $300 \mathrm{~mm} \times 300 \mathrm{~mm} \times 50 \mathrm{~mm}$ were prepared to perform the rutting test at $60^{\circ} \mathrm{C}$. The results are shown in Figure 10 .

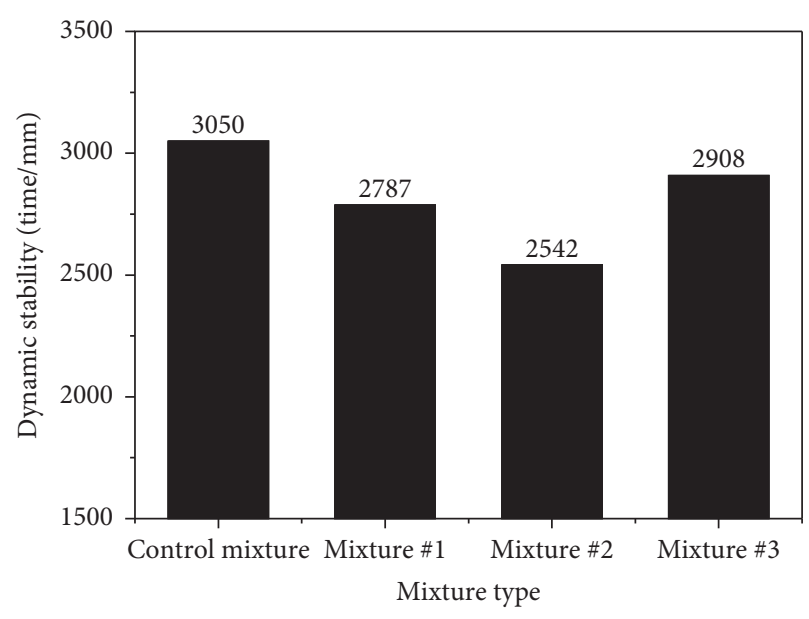

Figure 10: Results of dynamic stability.

The dynamic stability had a varying trend similar to that of shear strength. The addition of SC in Mixture \#2 and Mixture \#3 reduced the dynamic stability by $8.6 \%$ and $16.7 \%$, respectively, compared to that of control mixture. Similarly, the dynamic stability of Mixture \#3 was the highest among the three low-thermal-conductivity mixtures prepared in this study.

\section{Conclusions}

This work used SC and FAC to replace equal volumes of basalt aggregate and limestone mineral powder, respectively. In total, four kinds of asphalt mixtures were prepared and used to perform a series of experiments to confirm the possibility of enhancing the thermal resistance of asphalt mixture for cooling asphalt pavement.

SC and FAC are both featured of low density and high moisture absorption ratio, thus having lower thermal conductivity than basalt aggregate and limestone mineral powder, respectively. The ESEM test showed that there were many large pores in SC, and most of FAC looked like spherical particles. Using SC and FAC could produce lowthermal-conductivity asphalt mixture. The thermal conductivity of asphalt mixture could reduce by up to $35.3 \%$, which could be used to prevent solar radiation from transferring downwards. The low-thermal-conductivity asphalt mixture presented a maximum temperature reduction by $4.39^{\circ} \mathrm{C}$ at the depth of $4 \mathrm{~cm}$. However, the upper surface temperature increased, because more solar heat accumulated on the surface of asphalt pavement. Nevertheless, the mechanical performance for rutting resistance of asphalt mixture with addition of SC reduced, compared with control asphalt mixture, while FAC had a positive effect on this performance.

Overall, adding lightweight materials in asphalt mixture could improve thermal resistance and reduce the inner temperature of asphalt pavement. However, the reduced rutting resistance of this kind of mixture tells us that in future studies some reinforcing agents should be added to prepare low-thermal-conductivity asphalt mixture with high strength. 


\section{Data Availability}

The data used to support the findings of this study are available from the corresponding author upon request.

\section{Conflicts of Interest}

The authors declare that they have no conflicts of interest.

\section{Acknowledgments}

This work was financially supported by the Science and Technology Project of Highway Administration Bureau of Zhejiang Province, China (Grant number 2019H12) and National Natural Science Foundation of China (Grant number 51808562).

\section{References}

[1] A. Synnefa, T. Karlessi, N. Gaitani, M. Santamouris, D. N. Assimakopoulos, and C. Papakatsikas, "Experimental testing of cool colored thin layer asphalt and estimation of its potential to improve the urban microclimate," Building and Environment, vol. 46, no. 1, pp. 38-44, 2011.

[2] H. Li, J. Harvey, and A. Kendall, "Field measurement of albedo for different land cover materials and effects on thermal performance," Building and Environment, vol. 59, pp. 536546, 2013.

[3] A. Synnefa, M. Santamouris, and I. Livada, "A study of the thermal performance of reflective coatings for the urban environment," Solar Energy, vol. 80, no. 8, pp. 968-981, 2006.

[4] M. Santamouris, "Using cool pavements as a mitigation strategy to fight urban heat island-a review of the actual developments," Renewable and Sustainable Energy Reviews, vol. 26, pp. 224-240, 2013.

[5] Y. Qin, "A review on the development of cool pavements to mitigate urban heat island effect," Renewable and Sustainable Energy Reviews, vol. 52, pp. 445-459, 2015.

[6] Y. Du, J. Chen, Z. Han, and W. Liu, "A review on solutions for improving rutting resistance of asphalt pavement and test methods," Construction and Building Materials, vol. 168, pp. 893-905, 2018.

[7] P. F. Liu, J. Hu, H. Wang, F. G. Canon, D. W. Wang, and M. Oeser, "Influence of temperature on the mechanical response of asphalt mixtures using microstructural analysis and finite-element simulations," Journal of Materials in Civil Engineering, vol. 30, no. 12, Article ID 0401832, 2018.

[8] L. Zhang, C. Xing, F. Gao, T.-S. Li, and Y.-Q. Tan, "Using DSR and MSCR tests to characterize high temperature performance of different rubber modified asphalt," Construction and Building Materials, vol. 127, pp. 466-474, 2016.

[9] C. Wang, H. Wang, L. Zhao, and D. Cao, "Experimental study on rheological characteristics and performance of high modulus asphalt binder with different modifiers," Construction and Building Materials, vol. 155, pp. 26-36, 2017.

[10] J. Cai, J. Pei, Q. Luo, J. Zhang, R. Li, and X. Chen, "Comprehensive service properties evaluation of composite grouting materials with high-performance cement paste for semi-flexible pavement," Construction and Building Materials, vol. 153, pp. 544-556, 2017.

[11] A. Sha, Z. Liu, K. Tang, and P. Li, "Solar heating reflective coating layer (SHRCL) to cool the asphalt pavement surface,"
Construction and Building Materials, vol. 139, pp. 355-364, 2017.

[12] Y. Du, P. Liu, J. Wang et al., "Laboratory investigation of phase change effect of polyethylene glycolon on asphalt binder and mixture performance," Construction and Building $\mathrm{Ma}$ terials, vol. 212, pp. 1-9, 2019.

[13] W. Jiang, A. Sha, J. Xiao, Z. Wang, and A. Apeagyei, "Experimental study on materials composition design and mixture performance of water-retentive asphalt concrete," Construction and Building Materials, vol. 111, pp. 128-138, 2016.

[14] H. C. Dan, J. W. Tan, and J. Q. Chen, "Temperature distribution of asphalt bridge deck pavement with groundwater circulation temperature control system under high- and lowtemperature conditions," Road Materials and Pavement Design, vol. 4, pp. 1-19, 2017.

[15] J. Chen, H. Wang, M. Li, and L. Li, "Evaluation of pavement responses and performance with thermal modified asphalt mixture," Materials \& Design, vol. 111, pp. 88-97, 2016.

[16] Y. F. Du, Q. Shi, and S. Y. Wang, "Highly oriented heatinduced structure of asphalt pavement for reducing pavement temperature," Energ. Buildings.vol. 85, pp. 23-31, 2014.

[17] Y. F. Du, Q. Shi, and S. Y. Wang, "Bidirectional heat induced structure of asphalt pavement for reducing pavement temperature," Applied Thermal Engineering, vol. 75, pp. 298-306, 2015.

[18] J. J. Stempihar, T. Pourshams-Manzouri, K. E. Kaloush, and M. C. Rodezno, "Porous asphalt pavement temperature effects for urban heat island analysis," Transportation Research Record: Journal of the Transportation Research Board, vol. 2293, no. 1, pp. 123-130, 2012.

[19] A. Hassn, M. Aboufoul, Y. Wu, A. Dawson, and A. Garcia, "Effect of air voids content on thermal properties of asphalt mixtures," Construction and Building Materials, vol. 115, pp. 327-335, 2016.

[20] D.-W. Park and I.-T. Kim, “Thermal properties of permeable friction asphalt mixture and estimation of temperature profiles," International Journal of Pavement Engineering, vol. 14, no. 8, pp. 752-759, 2013.

[21] J. Chen, X. Yin, H. Wang, and Y. Ding, "Evaluation of durability and functional performance of porous polyurethane mixture in porous pavement," Journal of Cleaner Production, vol. 188, pp. 12-19, 2018.

[22] H. Wu, B. Sun, Z. Li, and J. Yu, "Characterizing thermal behaviors of various pavement materials and their thermal impacts on ambient environment," Journal of Cleaner Production, vol. 172, pp. 1358-1367, 2018.

[23] T. Asaeda and V. T. Ca, "Characteristics of permeable pavement during hot summer weather and impact on the thermal environment," Building and Environment, vol. 35, no. 4, pp. 363-375, 2000.

[24] M. Chen, J. Zheng, F. Li, S. Wu, J. Lin, and L. Wan, “Thermal performances of asphalt mixtures using recycled tyre rubber as mineral filler," Road Materials and Pavement Design, vol. 16, no. 2, pp. 379-391, 2015.

[25] Y. Q. Tan, L. Zhang, and X. Y. Zhang, "Investigation of lowtemperature properties of diatomite-modified asphalt mixtures," Construction and Building Materials, vol. 36, pp. 787-795, 2012.

[26] D. Feng, J. Yi, and D. Wang, "Performance and thermal evaluation of incorporating waste ceramic aggregates in wearing layer of asphalt pavement," Journal of Materials in Civil Engineering, vol. 25, no. 7, pp. 857-863, 2013. 
[27] Z. Zhang, Y. Luo, S. Huang, and K. Zhang, "Evaluation of temperature reduction and pavement performance of floating beads asphalt mixture," International Journal of Pavement Engineering, vol. 20, no. 3, pp. 349-356, 2017.

[28] A. Mohajerani, Y. Tanriverdi, B. T. Nguyen et al., "Physicomechanical properties of asphalt concrete incorporated with encapsulated cigarette butts," Construction and Building Materials, vol. 153, pp. 69-80, 2017.

[29] China Communications Press, Standard Test Methods of Bitumen and Bituminous Mixtures for Highway Engineering, China Communications Press, Beijing, China, 2011.

[30] Q. Li, X. Ma, F. Ni, and G. Li, "Characterization of strain rate and temperature-dependent shear properties of asphalt mixtures," Journal of Testing and Evaluation, vol. 43, no. 5, pp. 1120-1133, 2014.

[31] China Communications Press, Test Methods of Aggregate for Highway Engineering, China Communications Press, Beijing, China, 2005.

[32] J. Li, L. He, T. Liu, X. Cao, and H. Zhu, "Preparation and characterization of $\mathrm{PEG} / \mathrm{SiO}_{2}$ composites as shape-stabilized phase change materials for thermal energy storage," Solar Energy Materials and Solar Cells, vol. 118, pp. 48-53, 2013.

[33] A. Mohajerani, J. Bakaric, and T. Jeffrey-Bailey, "The urban heat island effect, its causes, and mitigation, with reference to the thermal properties of asphalt concrete," Journal of Environmental Management, vol. 197, pp. 522-538, 2017.

[34] N. Xie, H. Li, A. Abdelhady, and J. Harvey, "Laboratorial investigation on optical and thermal properties of cool pavement nano-coatings for urban heat island mitigation," Building and Environment, vol. 147, pp. 231-240, 2019.

[35] H. Wang, Q. Zhang, and J. Tan, "Investigation of layer contributions to asphalt pavement rutting," Journal of Materials in Civil Engineering, vol. 21, no. 4, pp. 181-185, 2009.

[36] T. Xu and X. Huang, "Investigation into causes of in-place rutting in asphalt pavement," Construction and Building Materials, vol. 28, no. 1, pp. 525-530, 2012.

[37] S. Tapkın, "Mechanical evaluation of asphalt-aggregate mixtures prepared with fly ash as a filler replacement," $\mathrm{Ca}$ nadian Journal of Civil Engineering, vol. 35, no. 1, pp. 27-40, 2008.

[38] M. Arabani and S. A. Tahami, "Assessment of mechanical properties of rice husk ash modified asphalt mixture," Construction and Building Materials, vol. 149, pp. 350-358, 2017. 


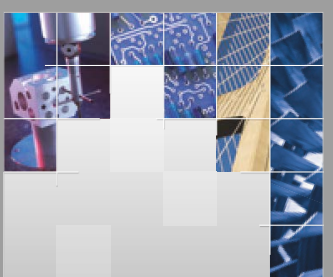

\section{Enfincering}
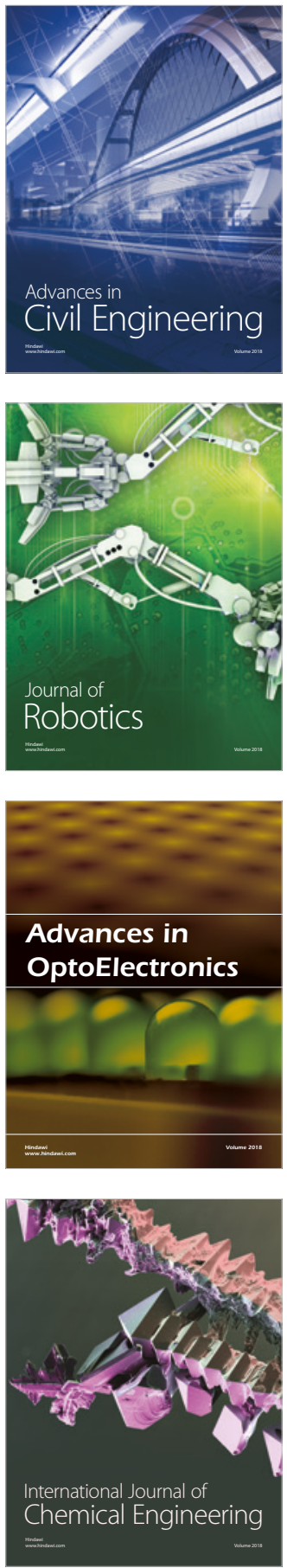

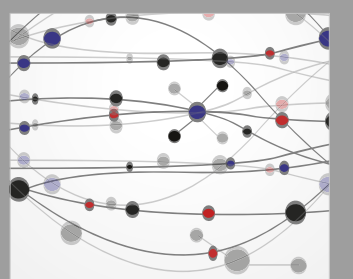

\section{Rotating \\ Machinery}

The Scientific World Journal

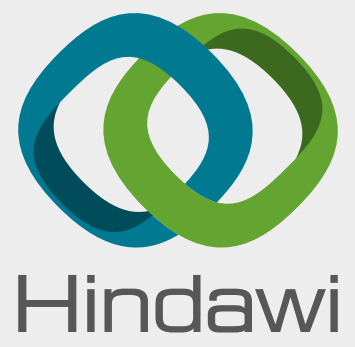

Submit your manuscripts at

www.hindawi.com
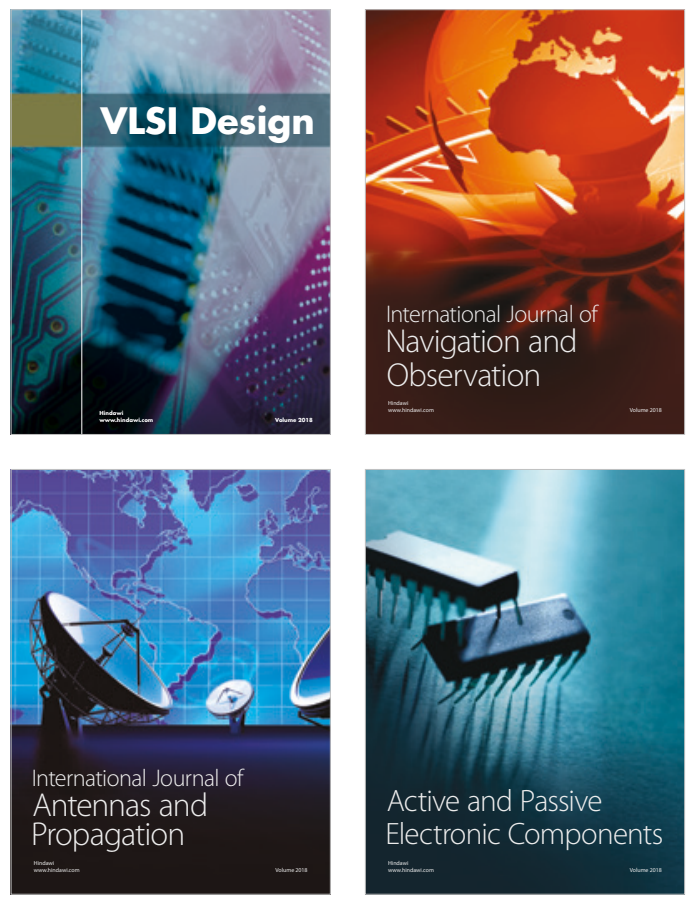
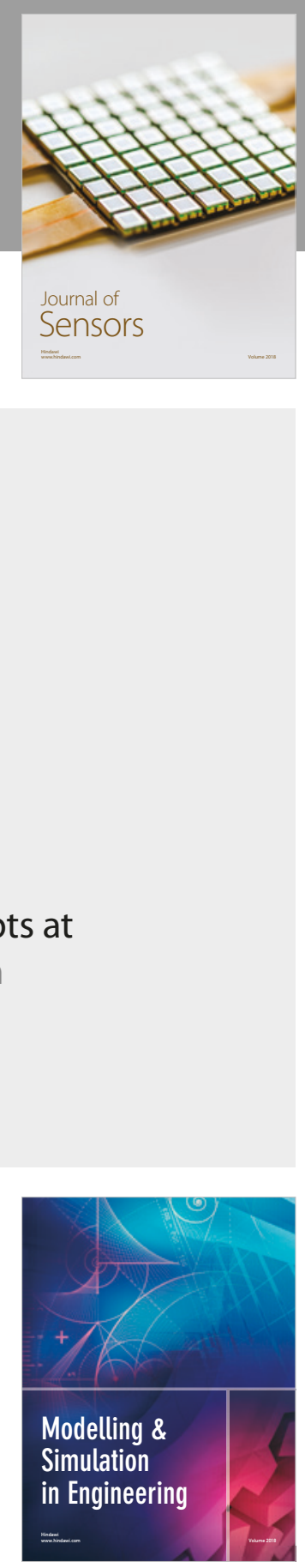

\section{Advances \\ Multimedia}
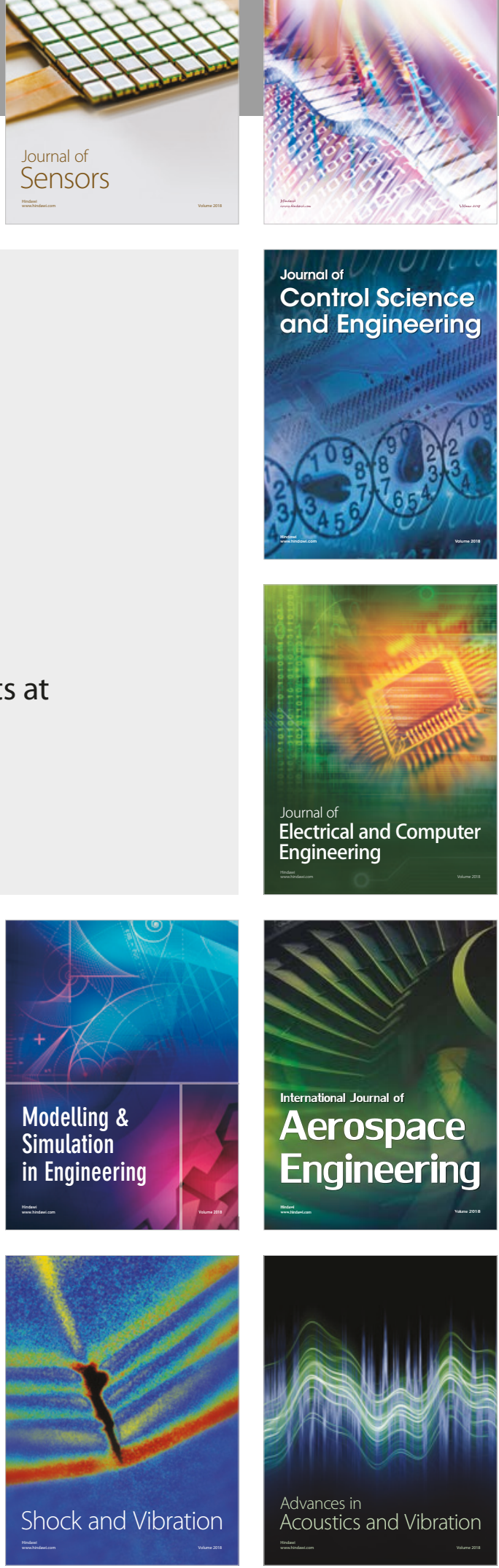